\title{
Deficits in Memory Tasks of Mice with CREB Mutations Depend on Gene Dosage
} Peter Gass, ${ }^{1,4}$ David P. Wolfer, ${ }^{2}$ Detlef Balschun, ${ }^{3}$ Dorothea Rudolph, ${ }^{1}$ Uwe Frey, ${ }^{3}$ Hans-Peter Lipp, ${ }^{2}$ and Günther Schütz ${ }^{1}$

${ }^{1}$ Department of Molecular Biology of the Cell I

German Cancer Research Institute

D-69120 Heidelberg, Germany

${ }^{2}$ Department of Anatomy

University of Zürich

Zürich, Switzerland

${ }^{3}$ Department of Gene Regulation and Plasticity

Federal Institute for Neurobiology

Magdeburg, Germany

\section{Abstract}

Studies in Aplysia, Drosopbila, and mice have shown that the transcription factor CREB is involved in formation and retention of long-term memory. To analyze the impact of differential CREB levels on learning and memory, we varied the gene dosage of CREB in two strains of mutant mice: (1) CREB $\alpha \Delta$ mice, in which the $\alpha$ and $\Delta$ isoforms are disrupted, but a third isoform $\beta$ is strongly up-regulated; (2) CREBcomp, a compound strain with one $\alpha \Delta$ allele and one CREBnull allele in which all CREB isoforms are disrupted. To minimize genetic background effects, CREB mutations were backcrossed into a $\mathrm{C} 57 \mathrm{BL} / 6$ and a FVB/N strain, respectively, and studies were performed in $F_{1}$ hybrids from these lines. CREBcomp but not $C R E B \alpha \Delta F_{1}$ hybrids were impaired in water maze learning and fear conditioning, demonstrating a CREB gene dosage effect. However, analysis of the platform searching strategies in the water maze task suggested that CREBcomp mutants are impaired in behavioral flexibility rather than in spatial memory. In contrast to previous experiments using CREB $\alpha \Delta$ mice with different genetic background, the $F_{1}$ hybrid CREB $\alpha \Delta$ and CREBcomp mice did not show deficits in a social transmission of food preference task nor in dentate gyrus and CA1 LTP as recorded from slice preparations. These data indicate that the hybrid vigor typical for $F_{1}$ hybrids may compensate for a reduction in CREB levels in some tests. On the other hand, the persistence of clear behavioral deficits as shown by the $F_{1}$ hybrid CREBcomp mice in water maze and fear conditioning indicates a robust and repeatable phenomenon that will permit further functional analysis of CREB.

\section{Introduction}

The transcription factor CREB (cAMP response element-binding) protein is activated by diverse signal transduction pathways influenced by cAMP and calcium and is thought to be involved in the neuronal signaling processes leading to the formation of long-term memory (LTM) (Frank and Greenberg 1994; Bailey et al. 1996). Recent studies in invertebrates [Aplysia (Dash et al. 1990; Bartsch et al. 1995); Drosophila (Yin et al. 1994, 1995)] and vertebrates [mice (Bourtchuladze et al. 1994; Kogan et al. 1996); rats (Guzowski and McGaugh 1997)] indicated that the specific role of CREB in LTM formation is conserved during evolution. CREB has been shown to participate in associative and nonassociative forms of learning as well as being critical for the consolidation of explicit and implicit memory. A coincidence of deficits in behavioral learning tasks and in electrophysiological correlates of learning and memory has been re-

LEARNING \& MEMORY 5:274-288 @ 1998 by Cold Spring Harbor Laboratory Press ISSN1072-0502/98 \$5.00

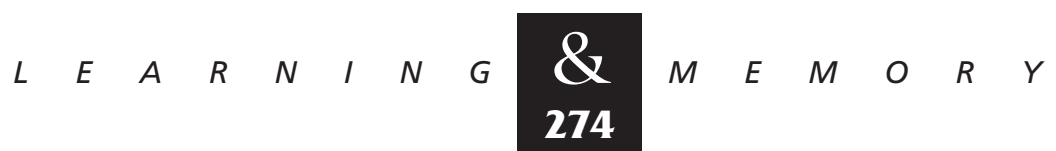


ported in both invertebrates (Dash et al. 1990; Bartsch et al. 1995) and vertebrates (Bourtchuladze et al. 1994) following manipulations of CREB genes or their products. Mice with a hypomorphic CREB allele generated by homologous recombination (Hummler et al. 1994) displayed deficits in water maze learning and fear conditioning that coincided with an impairment of long-term potentiation (LTP) (Bourtchuladze et al. 1994), a correlate of learning and memory at the cellular level (Bliss and Collingridge 1993). In these mice, the two major physiological isoforms of CREB, $\alpha$ and $\Delta$, are disrupted, whereas a third isoform, $\beta$, as well as several activator and repressor forms of CREM are up-regulated (Hummler et al. 1994; Blendy et al. 1996).

Recent studies have indicated that learning and memory in mice with and without specific genetic mutations are strongly influenced by the genetic background of the animals (Gerlai 1996; Owen et al. 1997; Wolfer et al. 1997; Giese et al. 1998; for review, see Lathe 1996). Thus, specific mutations can have different phenotypes in different genetic backgrounds (Hsiao et al. 1996; Banbury Conference on Genetic Background in Mice 1997; Wolfer et al. 1997). Because the identity of the genetic elements controlling these modifying factors are usually unknown, it is important to keep them constant when evaluating the impact of a mutation. To overcome strain-specific limitations of behavioral testing, use of $\mathrm{F}_{1}$ hybrids of two different inbred strains is recommended (Banbury Conference on Genetic Background in Mice 1997). This offers the advantage of hybrid vigor, that is, outperformance of the parental lines by the hybrids, but should also reduce the variability of learning tests, because all littermates have a similar genetic make-up (apart from the immediate vicinity of the mutated locus). It should further improve the reproducibility of specific phenotypes when analyzed in different laboratories or at later time points.

In view of these recent findings and recommendations, the earlier experiments with $\operatorname{CREB} \alpha \Delta$ mice have to be validated (Bourtchuladze et al. 1994; Kogan et al. 1996). The genetic background of these animals displaying deficits in water maze learning, fear conditioning, and LTP was a mixture of alleles from C57BL/6 and 129Svev (Bourtchuladze et al. 1994). A second study reproduced the behavioral deficits in fear conditioning and water maze tasks using CREB $\alpha \Delta$ mice predominantly on a C57BL/6 background (>87\%) or on an $F_{2}$ back- ground of C57BL/6x129SVJ, respectively (Kogan et al. 1996). The role of the genetic background was not systematically addressed. Therefore, we decided to investigate the role of CREB for behavioral learning and LTP in mice with a better defined genetic background, using $F_{1}$ hybrids. Furthermore, the availability of a mouse strain with disruption of all CREB isoforms (CREBnull) allowed us to study the effects of gene dosage (Rudolph et al. 1998). Although mice homozygous for this mutation turned out to be lethal owing to postnatal respiratory failure, heterozygous mice can be used to further reduce the CREB gene dosage of $\operatorname{CREB} \alpha \Delta$ animals by intercrossing. This resulted in a mouse strain with only one allele coding for the $\beta$ isoform, which survives without any gross abnormalities in behavior (Rudolph et al. 1998). For the present study, CREB $\alpha \Delta$ and CREBnull mutations were backcrossed into the $\mathrm{C} 57 \mathrm{BL} / 6$ and the FVB/N background, respectively. $F_{1}$ hybrids with a stepwise loss of CREB gene dosage were generated from intercrosses of these lines: CREB $\alpha \Delta$ mice with two $\alpha \Delta$ alleles and compound mice (CREBcomp) with one $\alpha \Delta$ and one null allele. The present study analyzed the effects of these mutations on different behavioral learning and LTP paradigms.

\section{Materials and Methods}

ANIMALS

Generation of the CREB $\alpha \Delta$ and the CREBnull alleles has been described elsewhere (Hummler et al. 1994; Blendy et al. 1996; Rudolph et al. 1998). The $\operatorname{CREB} \alpha \Delta$ allele was backcrossed into the C57BL/6 background and the FVB/N background (both from Charles River, Sulzfeld, Germany), the CREBnull allele was backcrossed into the C57BL/6 background. All experiments were performed in $\mathrm{F}_{1}$ hybrid mice that were progeny from intercrosses of $F_{6}$ or $F_{7}$ backcross generations of these two backgrounds. We investigated $\mathrm{F}_{1}$ hybrid wild-type mice, $\mathrm{F}_{1}$ hybrids homozygous for the $\alpha \Delta$ allele $(=\operatorname{CREB} \alpha \Delta)$, and $\mathrm{F}_{1}$ hybrids with one $\alpha \Delta$ and one null allele (= CREBcomp). Ten wild-type mice and 10 CREBcomp mice used in the first version of the water maze (six trials per day, see below) were derived from intercrosses of $\mathrm{F}_{6}$ backcross generations, as well as the 10 wild-type mice and 10 CREBcomp mice used for the social transmission of food preference studies. All other studies were performed in intercrosses from $F_{7}$ backcross genera-

$$
\begin{array}{llllllllllllllll}
\mathbf{Q} & E & A & R & N & I & N & G & M & E & M & O & R & Y \\
\mathbf{2 7 5} & & & & & &
\end{array}
$$


tions. In the fear conditioning study, an $\mathrm{F}_{2}$ progeny from C57BL/6 and 129/Svev was used as an additional control group. Genotyping was carried out with the PCR on tail DNA samples (Rudolph et al. 1998). All experiments were performed blindly with respect to the genotype of the mice. All experiments were performed with mice 2-6 months old, and a similar number of males and females were used. Mice were kept on a 12:12-hr lightdark cycle. All experiments were performed during the light phase of the cycle, with the exception of the water maze studies that were conducted during the dark cycle.

\section{WATER MAZE STUDIES}

Morris water maze experiments were performed in the same water maze with two different training protocols (Morris et al. 1982). One version comprised six training trials per day with 1-hr intertrial intervals, which has been used to study nearly 2000 mice during recent years (Wolfer et al. 1997; D.P. Wilfer, M. Bozicevic-Stagliar, and H.P. Lipp, unpubl.). A second version consisted of two training trials per day and a 1-min intertrial interval, which had been used to characterize $\operatorname{CREB} \alpha \Delta$ mice in earlier experiments by Kogan et al. (1996). Pool, platform, and visual cues were identical as described earlier (Wolfer et al. 1997; D.P. Wolfer, M. Bozicevic-Stagliar, and H.P. Lipp, unpubl.). The swim paths of the mice were recorded using a video camera suspended above the center of the pool and were fed to an electronic imaging system recording the $x y$-coordinates (Noldus EthoVision 1.90.). The recorded paths were analyzed off-line by special software (WINTRACK, by D.P. Wolfer). The following variables were analyzed: time to find platform (s), length of swim path (m), swim speed while moving $(\mathrm{m} / \mathrm{s})$, percent of time spent floating, percent of time spent within a rim of $22 \mathrm{~cm}$ from the wall (thigmotaxis), percent of time swimming in parallel to the wall, number of wall touches, percent of time in target quadrant, average distance to the target, percent of time spent in former target quadrant and other quadrants, and number of annulus crossings over the former platform position and over the annulus in control quadrants. In the first version of the test, 19 wildtype, $12 \mathrm{CREB} \alpha \Delta$, and $18 \mathrm{CREBComp}$ mice were investigated. The entire procedure took 5 days; each mouse did a total of 30 trials, 6 trials per day with a 1-hr intertrial interval. The position of the hidden platform remained fixed for the first 3 days
(18 trials, acquisition phase). Afterwards, it was placed in the opposite quadrant for 2 days (12 trials, reversal phase). In all trials, mice were left swimming until they found the platform or $120 \mathrm{sec}$ had elapsed. The first $60 \mathrm{sec}$ of the first trial during the reversal phase served as probe trial for spatial retention. In the other schedule of the test, 14 wild-type, $10 \mathrm{CREB} \alpha \Delta$ and $13 \mathrm{CREBcomp}$ mice were investigated. Animals had only two training trials per day (with an interval of $1 \mathrm{~min}$ ) over a period of 14 consecutive days. The 1-min intertrial interval was spent on the platform. If an animal did not find the platform in the first trial, it was placed on it after $1 \mathrm{~min}$. Probe trial (free swimming without the platform in the pool) was performed on day 10 and day 15. Statistical analysis of learning curves was done on average blocks of two trials in both schedules. Data were analyzed by a repeated two-way analysis of variance (ANOVA) for genotype (CREBwildtype, CREB $\alpha \Delta$, CREBcomp) and trial block within subjects (either 14 or 15 depending on schedule). Analysis of probe trials (spatial retention) included genotype (as above) and quadrant times (or platform/annulus crossings) as repeated factors (old target quadrant vs. averaged adjacent control quadrants). Differences between groups were analyzed by planned post hoc Scheffe comparisons. Because the direction of the CREB and schedule effects were predicted from earlier studies, the probabilities for pairwise comparisons of groups are given as one-tailed $P$ values if not mentioned otherwise.

\section{FEAR CONDITIONING STUDIES}

The conditioning system (commercially available from TSE, Bad Homburg, Germany) consisted of a soundproof box $\left(58 \times 30 \times 27 \mathrm{~cm}^{3}\right)$ with a gray interior, a 12-V light at the ceiling, a fan, a speaker, and a Plexiglas chamber $(35 \times 20 \times 20$ $\mathrm{cm}^{3}$ ) that was placed on a shock grid made of stainless steel rods $(0.4 \mathrm{~cm}$ diam., spaced $0.9 \mathrm{~cm}$ apart $)$. The grid was connected to a shocker/scrambler unit delivering shocks of defined duration and intensity. Experiments were performed according to the protocol of Bourtchuladze et al. (1994). For both contextual and cued conditioning experiments, mice were placed into the Plexiglas chamber for 2 min before the onset of a discrete conditioned stimulus $(2.800-\mathrm{Hz}$ tone, $85 \mathrm{~dB})$ that lasted $30 \mathrm{sec}$. At the end of the tone, animals were subjected to the unconditioned stimulus (2 sec of continuous footshock at $0.75 \mathrm{~mA}$ ). Animals were left in

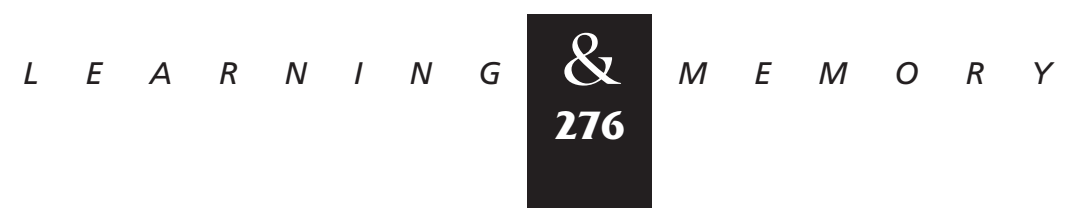


the conditioning chamber for another $30 \mathrm{sec}$ and were then placed back into their home cages. Conditioning was assessed by measuring freezing, defined as a complete lack of movement besides respiration. For contextual conditioning, freezing was measured for $5 \mathrm{~min}$ in the chamber in which the animals were trained. For analyzing cued conditioning, animals were placed in a novel context (triangular cage with nongrid floor) for $3 \mathrm{~min}$, after which they were exposed to the conditioned stimulus for another $3 \mathrm{~min}$. For contextual and cued conditioning, freezing was scored in 10-sec intervals, and the score was calculated in percent of total observation time. The retention of freezing $24 \mathrm{hr}$ after training was investigated in $20 \mathrm{~F}_{1}$ wildtype, $12 \mathrm{~F}_{1} \mathrm{CREB} \alpha \Delta$, and $12 \mathrm{~F}_{1}$ CREBcomp mice, and furthermore in 12 animals of pure $\mathrm{C} 57 \mathrm{BL} / 6$ background and 18 animals that were an $\mathrm{F}_{2}$ progeny from C57BL/6 and 129Svev. Short-term memory ( 0.5 -hr test) was analyzed in 12 wild-type, $12 \operatorname{CREB} \alpha \Delta$, and 12 CREBcomp mice, all $\mathrm{F}_{1}$ hybrids. For statistical analysis of the data, a one-way ANOVA was used to analyze performance across the different groups for contextual and cued conditioning, respectively. Student's $t$-test in combination with the Bonferroni/Dunn correction was applied for post-hoc comparisons of specific pairs of experimental groups. Errors indicated are standard errors of the mean (S.E.M.).

\section{SOCIAL TRANSMISSION OF FOOD} PREFERENCE STUDIES

The social transmission of food preference task was in principle performed as described by Kogan and colleagues (1996). Training and testing comprised three main stages. First, a demonstrator mouse was allowed to eat powdered ground chow scented with either cinnamon ( $1 \% \mathrm{wt} / \mathrm{wt})$ or cocoa $(2 \% \mathrm{wt} / \mathrm{wt})$. Second, the demonstrator mouse (for cinnamon or cocoa, respectively) and a littermate observer mouse (= memory-tested mouse) were allowed to freely interact for $10 \mathrm{~min}$. In contrast to the protocol of Kogan et al. (1996), only one demonstrator mouse was used for each litter (for a 10-min continuous interaction) instead of two different demonstrator mice (for two 5-min interactions spaced by $1 \mathrm{~min}$ ), because some litters did not contain enough wild-type mice to choose two demonstrators. To avoid a potential bias for one scent, half of the mice were presented with cinnamon-scented food and the other half with cocoa-scented food. In the third phase, observer mice were tested for food preference $24 \mathrm{hr}$ following the interaction session. They were given a free choice between two food cups with cinnamon or cocoa, respectively, for $2 \mathrm{hr}$. Thereafter, the total amount of each food eaten was determined. Twenty-one wild-type, $10 \mathrm{CREB} \alpha \Delta$, and $10 \mathrm{CREB}-$ comp mice were tested. Student's $t$-test was applied for comparison of the total amount of cued food versus noncued food eaten by each group (wild type, CREB $\alpha \Delta$, CREBcomp). Errors indicated are s.E.M.

LTP

Electrophysiological recordings were performed as described previously (Frey et al. 1988, 1996), except that the mice were briefly anesthetized $(<15 \mathrm{sec})$ with chloroform before decapitation. For recordings in the CA1 region, slices were incubated in an interface chamber at $32^{\circ} \mathrm{C}$ and a flow rate of artificial cerebrospinal fluid (ACSF) of $1 \mathrm{ml} / \mathrm{min}$. After a 4- to 5 -hr preincubation period, two monopolar, lacquer-coated, stainless-steel electrodes were placed in different sublayers of the stratum radiatum to stimulate two different inputs to the same population of pyramidal cells. For recording, two electrodes were positioned in the CA1 dendritic and cell body layer. The population spike $(\mathrm{mV})$ was evaluated by taking the voltage difference between onset and peak. The slope function $(\mathrm{mV} / \mathrm{msec})$ of the field excitatory postsynaptic potential (fEPSP) was calculated from eight successive points of the steepest $400-\mu s e c$ segment. Subsequently, input/output (I/O) curves were constructed, and the stimulation strength was adjusted to elicit a population spike of $25 \%$ of the maximum. Once stable, responses were obtained for $60 \mathrm{~min}$; LTP was induced in one input by either a "weak" or a "strong" tetanization protocol. The weak tetanization protocol consisted of 21 pulses at $100 \mathrm{~Hz}$ (duration, $0.2 \mathrm{msec}$ per polarity); the strong tetanization protocol consisted of three stimulus trains of 100 pulses at $100 \mathrm{~Hz}$, with a 10-min intertrain interval (duration, $0.2 \mathrm{msec}$ per polarity). The weak tetanization protocol induces a protein synthesis-independent, decremental potentiation under most circumstances, whereas the strong paradigm was repeatedly described to generate protein synthesis-dependent late LTP (Frey et al. 1988; Frey and Morris 1997). Four 0.2-Hz biphasic, constant-current pulses $(0.1 \mathrm{msec}$ per polarity) were used for testing $1,3,5,11,15,21,25$, and 30 min post-tetanus and thereafter once every $15 \mathrm{~min}$.

$$
\begin{array}{lllllllllllllll}
\hline & E & A & R & N & I & N & G & \underset{\mathbf{2 7 7}}{\boldsymbol{Z}} & M & E & M & O & R & Y
\end{array}
$$


LTP was recorded for at least $2 \mathrm{hr}$ and evaluated by the initial magnitude of potentiation ( $1 \mathrm{~min}$ after tetanus), and the maintanance of potentiation was assessed $2 \mathrm{hr}$ post-tetanus.

The recording in the dentate gyrus was conducted as in CA1 with the following exceptions: Slices were kept in a submerged slice chamber, and a monopolar, lacquer-coated steel electrode was placed in the stratum moleculare of the dentate gyrus to stimulate the medial perforant-path input, which was distinguished by its localization and the presence of paired pulse depression at an interpulse interval of $40 \mathrm{msec}$. The recording electrode was lowered to the same level, but $\sim 200 \mu \mathrm{m}$ apart to record fEPSPs. After I/O curves were generated by recording fEPSP slopes at an increasing stimulation intensity, the stimulation voltage was adjusted to elicit a fEPSP slope of $35 \%$ of the maximum. LTP was induced by a triple tetanization consisting of 15 bursts of eight pulses at $200 \mathrm{~Hz}$, with an interburst interval of $200 \mathrm{msec}$, applied three times every $10 \mathrm{~min}$. In all experiments, the recording of slices from mutant mice was interleaved by experiments with wild-type controls. Statistical analysis was performed using the two-tailed MannWhitney $U$ test (between-group differences) and the Wilcoxon matched pairs signed-rank test (within group differences) at a significance level of $P<0.05$.

\section{Results}

LEARNING PERFORMANCE AND SPATIAL

RETENTION IN THE WATER MAZE TASK ARE

DEPENDENT ON GENE DOSAGE OF CREB

Two different protocols of the water maze test were used. All statistical data for the parameters investigated in both schedules are given in Table 1. In the more intense schedule with six training trials per day, all three genotypes $\left(\mathrm{F}_{1}\right.$ hybrid wild types and $\mathrm{CREB} \alpha \Delta$ and CREBcomp mice) demonstrated improvement of escape performance during aquisition and reversal phase as revealed by decreasing swim path lengths (Fig. 1A). However, performance was not the same in the groups as revealed by ANOVA for path length $(P<0.027$; Fig. 1A). Comparisons between groups showed small but significant differences between wild-type mice and CREBcomp animals as well as between $\mathrm{CREB} \alpha \Delta$ and CREBcomp ( $P<0.05$, respectively) but surprisingly not between wild-type and $\mathrm{CREB} \alpha \Delta$ mice. During the probe trial, wild-type and $\mathrm{CREB} \alpha \Delta$ mice exhibited a significant prefer- ence for the trained goal position (Fig. 1C). They spent $\sim 40 \%$ of their time in the trained quadrant (as compared with the left and right control sites) and crossed the trained goal position (annulus crossing) approximately three times more often than the respective sites of the adjacent quadrants (Fig. 1D). With respect to annulus crossings, CREBcomp mice differed significantly from wild types and failed to show a preference for the trained location ( $P<0.038$; Fig. 1D). However, CREBcomp mice did not differ statistically from wild types with respect to relative quadrant time, even though they spent only $\sim 35 \%$ of their time in the trained quadrant (Fig. 1C). No significant differences were found for swim speed, percentage of time floating passively, or sex effects.

Because this training protocol may have been too stringent to detect more subtle differences between the three genotypes, we tested another set of animals in a protocol that has been reported to be more sensitive for the detection of LTM deficits in mice with CREB mutations (Kogan et al. 1996). Using two training trials per day with a 1-min intertrial interval, all three genotypes improved during the training period (Fig. 2A). Performance was not the same in all groups as shown by ANOVA for path lenght $(P<0.017$; Table 1$)$. Post-hoc comparisons exhibited significantly longer escape paths for CREBcomp mice than wild-type controls $(P<0.01)$ as well as an increased average distance to the goal ( $P<0.002$, data not shown). CREB $\alpha \Delta$ were in between wild types and CREBcomp mice. They had slightly longer paths than controls, but this trend was not significant. However, they showed an increased average distance to the goal as compared with controls ( $P<0.05$; data not shown). Probe trials demonstrated moderately significant effects of CREB deficiency on spatial retention $(P<0.045)$. Wild-type controls spent $38 \%$ of their time in the trained quadrant (Fig. 2C), and crossed the trained goal position approximately twice as often as adjacent control sites (Fig. 2D). With respect to both relative quadrant time and annulus crossings, CREB $\alpha \Delta$ mice did not differ statistically from wild-type mice, even though they spent, on average, only $33 \%$ of their time in the trained quadrant (Fig. 2C,D). In contrast, CREBcomp animals searched only at chance level (26\%), leading to a significant difference with respect to place preference when compared with controls $(P<0.01$; Fig. $2 \mathrm{C})$. The number of annulus crossings showed the same order of groups (wild-types $>$ REB $\alpha \Delta>$ CREBcomp); however, the variability of scores pre-

$$
\begin{array}{llllllllllllllll}
\hline & E & A & R & N & I & N & G & \boldsymbol{\&} \\
\mathbf{2 7 8} & M & E & M & O & R & Y
\end{array}
$$


Table 1: ANOVA in two samples of mice trained using different water maze schedules

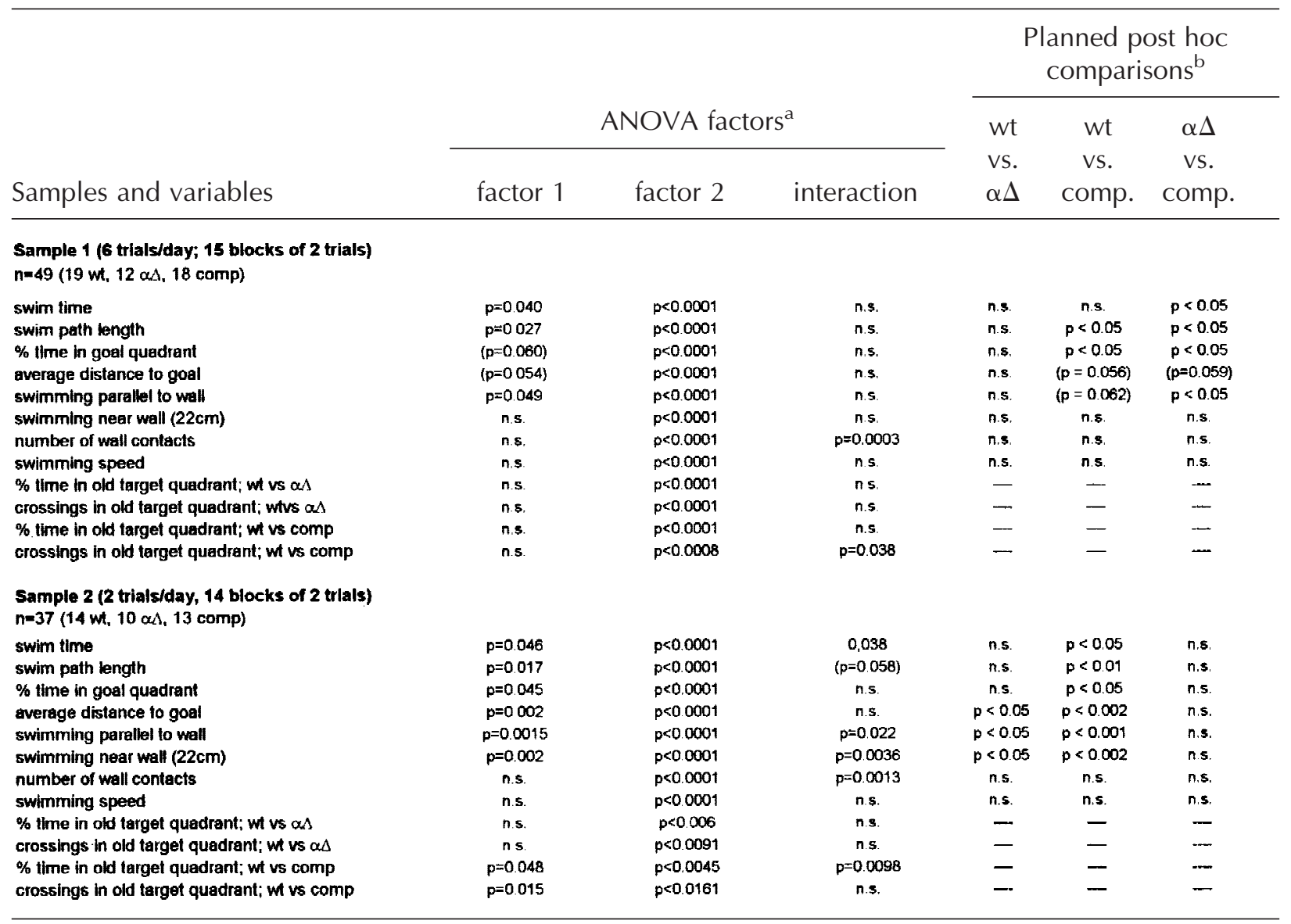

(n.s.) Not significant.

a(Factor 1) Genotype; (factor 2) trial blocks or quadrants; (interaction) genotype $\times$ trial blocks/quad.

${ }^{b}(\alpha \Delta)$ CREB $\alpha / \Delta$ mutants; (comp.) CREBcomp mutants; (wt) wild types. ( $P=0.0 x x$ ) Statistical trend. $P$ values one-tailed, Scheffe.

vented significant genotype $\times$ place interactions as well as significant pairwise differences between genotypes. An additional probe trial had already been performed at day 10 to exclude the possibility that more pronounced differences between wild-type and $\mathrm{CREB} \alpha \Delta$ mice were present at an earlier time point (data not shown). Although performance of CREBcomp mice did not improve between day 10 and day 14, performance of wild-type and $\mathrm{CREB} \alpha \Delta$ animals improved in parallel, that is, the deficits between wild-type and $\operatorname{CREB} \alpha \Delta$ mice on the one hand and CREBcomp mice on the other were more evident after 14 days than after 10 days of training.

In summary, no statistically significant deficits were found for $\mathrm{CREB} \alpha \Delta$ mice in the six trials per day test, whereas CREBcomp animals showed weak deficits in acquisition of the task (path length) and memory retention (annulus crossings) (Fig. 1). In the two trials per day version, $\mathrm{CREB} \alpha \Delta$ mice showed a performance intermediate between wild-type and CREBcomp mice. Whereas the deficits of $\mathrm{CREB} \alpha \Delta$ mice were statistically only significant for one measure during acquisition (average distance to goal), CREBcomp animals were severely impaired in both acquisition and quadrant time (Fig. 2).

\section{THIGMOTAXIS IS DEPENDENT ON GENE DOSAGE}

OF CREB AND CORRELATES WITH LEARNING PERFORMANCE AND SPATIAL RETENTION

IN THE WATER MAZE

Spatial learning deficits are commonly defined as lack of spatial preference toward an invisible

$$
\begin{array}{llllllllllllllll}
L & E & A & R & N & I & N & G & \begin{array}{l}
\boldsymbol{Z} \\
\mathbf{2 7 9}
\end{array} & M & E & M & O & R & Y
\end{array}
$$


Gass et al.

A

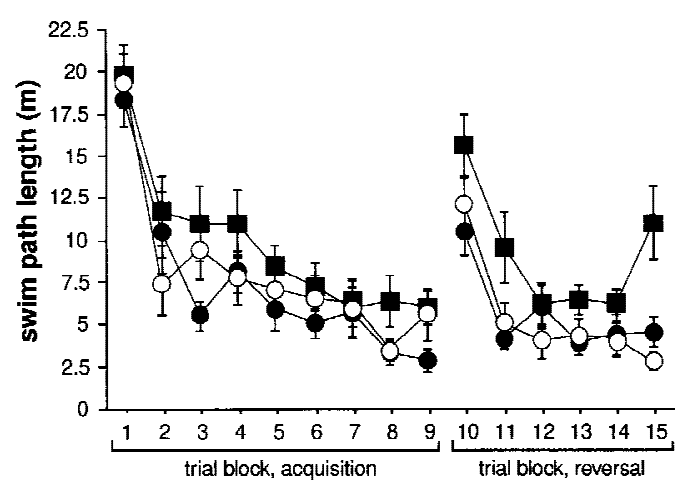

\section{C}

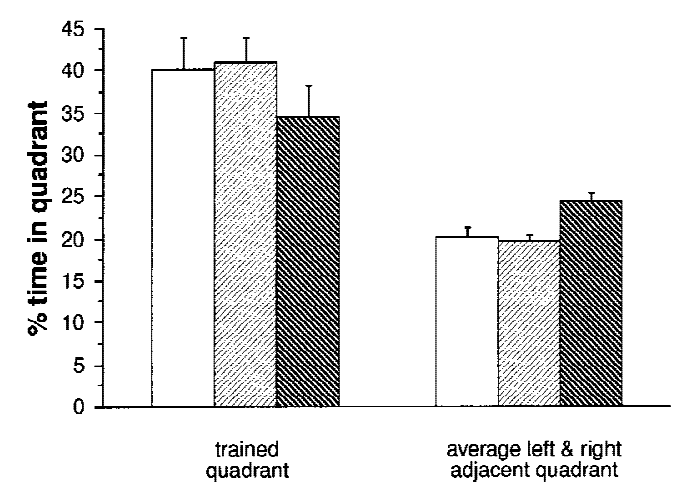

B

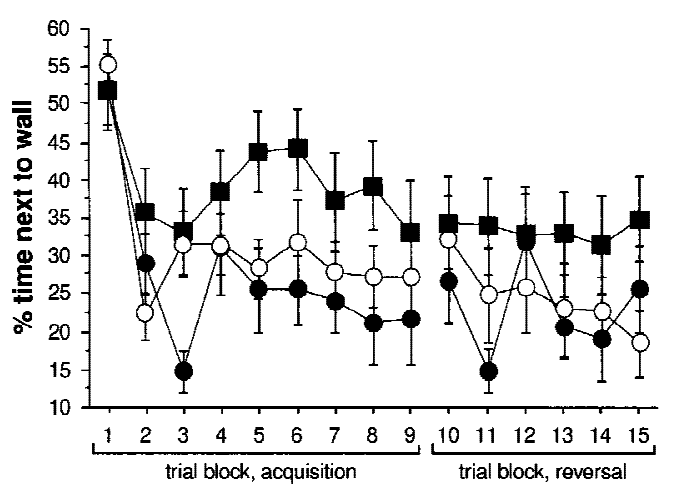

D

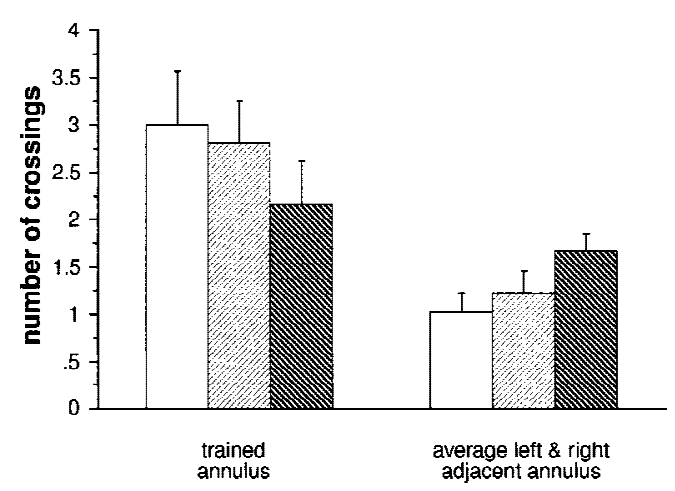

Figure 1: Subtle deficits in CREBcomp but not in CREB $\alpha \Delta$ mice in the water maze task with six trials per day and a 1-hr intertrial interval. $(A)$ The three groups show different aquisition of the task (path averaged over blocks of two trials, $P<0.027)$. CREBcomp mice have longer paths than wild types $(P<0.05)$, whereas CREB $\alpha \Delta$ mice are indistinguishable. $(B)$ The three groups are not significantly different with respect to the percent of time spent within $22 \mathrm{~cm}$ of the pool wall. $(A, B)(\bigcirc)$ Wild type; $(\mathbf{O})$ CREB $\alpha \Delta ;(\boldsymbol{\square})$ CREBcomp. (C) Comparison of percent time spent in the trained vs. adjacent left and right quadrants during the probe trial (first $60 \mathrm{sec}$ of the first reversal trial). Neither CREB $\alpha \Delta$ nor CREBcomp mice differ from wild types with respect to their clear preference for the trained quadrant. $(D)$ Comparison of number of crossings over the trained goal vs. left and right control annulus during the probe trial (first $60 \mathrm{sec}$ of the first reversal trial). (C, $D)(O p e n$ box) Wild type; (light hatching) CREB $\alpha \Delta$; (dark hatching) CREBcomp. CREB $\alpha \Delta$ have the same preference for the trained annulus as wild types. CREBcomp mice show a weaker preference for the trained annulus than wild types $(P<0.038)$.

goal position. However, spatial learning can take place by using alternative strategies without goal preferences, such as circular search paths. This strategy is often associated with, and probably derived from, thigmotaxis (swimming along the walls of the pool), the instinctive approaching of the walls most prevalent during the first trials of water maze learning (Lipp and Wolfer 1998). It has been shown that performance variations in swimming navigation learning of normal and transgenic mice are dependent on three independent factors: spatial memory, thigmotaxis, and swimming speed. An increase or persistence in thigmotaxis may sometimes be confounded with memory deficits
(Lipp and Wolfer 1998). Analyzing thigmotactic behavior (time spent near wall, percent swimming parallel to wall, number of wall contacts; cf. Table 1 and Fig. 1B) in the three groups demonstratedowing to the large variabilities of the scores-only borderline effects for the intense training protocol (parallel to wall swimming $P<0.048$ ). However, CREBcomp mice showed higher levels of thigmotaxis throughout aquisition as well as during reversal learning (Fig. 1B). Although no significant genotype effect was found for the number of wall contacts, this variable showed a highly significant interaction between genotype and trial blocks, indicating a persisting tendency of CREBcomp mice

$$
\begin{array}{lllllllllllllll}
L & E & A & R & N & I & N & G & \begin{array}{c}
\boldsymbol{Q} \\
\mathbf{2 8 0}
\end{array} & M & E & M & O & R & Y
\end{array}
$$


A

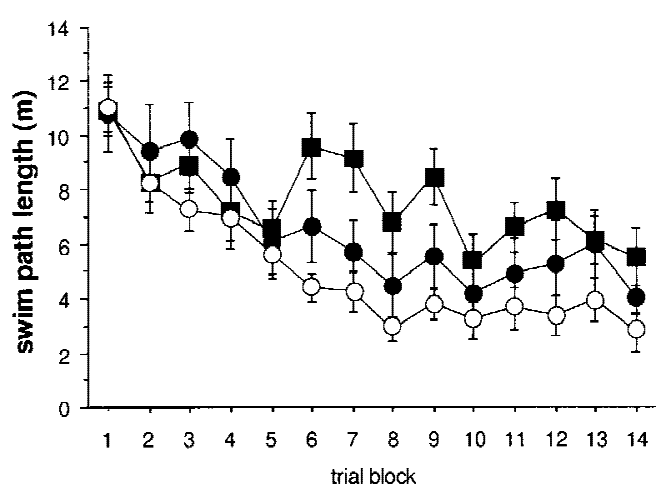

C

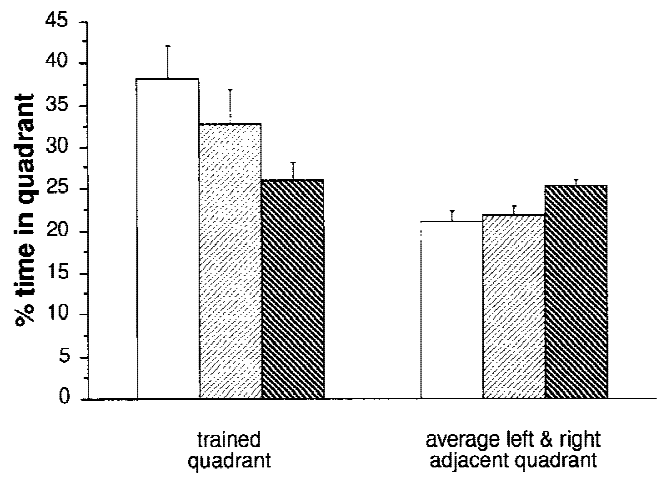

B

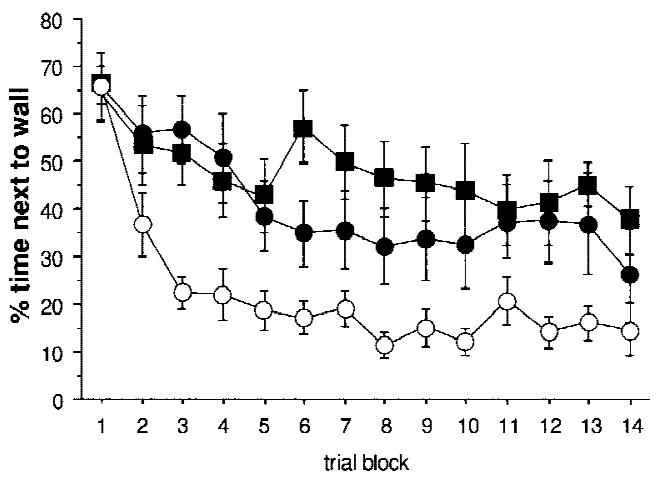

D

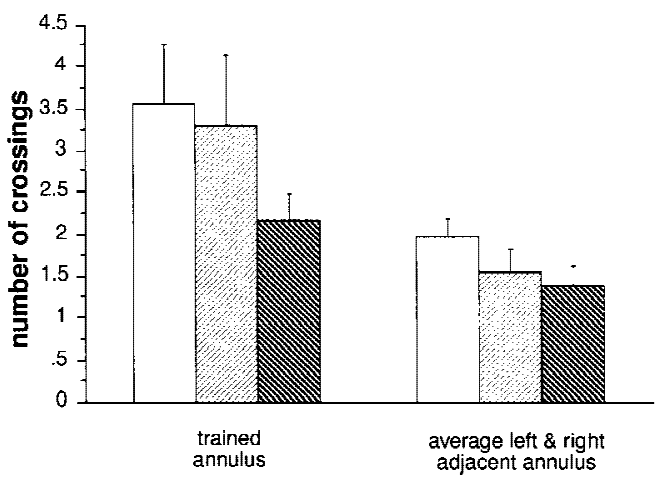

Figure 2: Larger and partially gradual deficits of CREB $\alpha \Delta$ and CREBcomp mutants in the water maze task with two trials per day and a 1-min intertrial interval. $(A)$ The three groups show aquisition of the task ranked according to gene dosage (path averaged over blocks of two trials, $P<0.017)$. CREBcomp mice have longer paths than wild types $(P<0.01)$, but $\mathrm{CREB} \alpha \Delta$ mice are statistically indistinguishable from wild types. $(B)$ The three groups differ with respect to the percent of time spent within $22 \mathrm{~cm}$ of the pool wall $(P<0.002)$. CREBcomp mice $(P<0.0015)$ as well as CREB $\alpha \Delta(P<0.05)$ spend more time next to the wall than wild types. $(C)$ Comparison of percent time spent in the trained vs. adjacent left and right quadrants during the $60 \mathrm{sec}$ probe trial. $\mathrm{CREB} \alpha \Delta$ mice show statistically the same preference for the trained quadrants as wild types. Unlike wild types, CREBcomp mice do not show a preference for the trained quadrant $(P<0.01)$. $(D)$ Comparison of number of crossings over the trained goal vs. left and right control annulus during the probe trial. CREB $\alpha \Delta$ have the same preference for the trained annulus as wild types. CREBcomp mice show overall fewer annulus crossings than wild types $(P<0.015)$ but are indistinguishable with respect to preference for the trained annulus. (See Fig. 1 for symbols.)

to make wall contacts during ongoing training. The thigmotactic tendencies of CREB mutant mice were clearly more evident under the less intense training schedule (Fig. 2B). ANOVA revealed highly significant genotype effects for swimming parallel to wall $(P<0.0015)$ and for time spent near the wall $(P<0.002)$. Pairwise comparisons of genotypes showed significant differences between wildtype and CREBcomp mice for swimming parallel to the wall $(P<0.0017)$, as well as for time spent near the wall between wild-type and CREBcomp animals $(P<0.0015)$ and wild-type and $\mathrm{CREB} \alpha \Delta$ mice
$(P<0.023)$. Because ANOVA had shown almost no significant differences in thigmotaxis under the intense training schedule, we also compared statistically the effects of genotype and training schedule on thigmotaxis. This could be done because the average score from both schedules was based on almost the same number of trials and because the score was not dependent on the different time schedules of the two protocols. A two-way ANOVA (genotype by schedule) revealed a highly significant genotype effect across both schedules $(P<0.0001)$, the CREBcomp mice being most thig-

$$
\begin{array}{llllllllllllllll}
\hline & E & A & R & N & I & N & G & \begin{array}{l}
\boldsymbol{Z} \\
\mathbf{2 8 1}
\end{array} & M & E & M & O & R & Y
\end{array}
$$


motactic in both conditions, and a moderate yet significant increase from an average of $30 \%$ thigmotactic swimming time to $36 \%$ under the less intense training schedule $(P=0.045)$. The lack of a significant interaction between the two factors indicates that the less intense training protocol merely accentuated the thigmotactic tendencies of mutant mice already present in the other protocol. Finally, a factor analysis using six variables comparable across the two water maze protocols showed that the behavior of the mice could be explained by three independent factors: thigmotaxis, speed and spatial memory (Table 2). This agrees completely with factor analyses conducted with large numbers of mice (Lipp and Wolfer 1998). Unlike conventional ANOVA, such factor analyses "subtract" statistically the amount of spatial memory score impairments attributable to thigmotaxis. The resulting factor, "spatial memory" (factor 3 in Table 2), indicates thus the proportion of variability in the spatial memory scores that is not accounted for by the factors thigmotaxis and speed. By entering the genotype in coded form (scoring CREBcomp as $-1, \operatorname{CREB} \alpha \Delta$ as 0 , and wild-type mice as 1), it is possible to check whether one of the factors is preferentially associated with genotype differences. Table 2 demonstrates that the variable genotype was associated strongly and only with the factor thigmotaxis but not with the spatial memory factor. This result reflects that a minority of CREBcomp mice showed good probe trial scores, and it implies that the impairment of spatial memory in the probe trials of CREBcomp mice as revealed by ANOVA was most likely owing to a majority of mice with increased thigmotactic behavior.
RETENTION OF FREEZING AFTER FEAR CONDITIONING IS DEPENDENT ON GENE DOSAGE

When tested for contextual as well as cued fear conditioning, $F_{1}$ hybrid wild-type mice revealed significantly less freezing than pure $\mathrm{C} 57 \mathrm{BL} / 6$ mice and the $\mathrm{F}_{2}$ progeny from $\mathrm{C} 57 \mathrm{BL} / 6$ and 129Svev (Fig. 3A). The latter two strains, which were used as independent controls for the test, demonstrated freezing scores as expected from the literature (Owen et al. 1997). Pure $\mathrm{C} 57 \mathrm{BL} / 6$ and $\mathrm{F}_{2}$ progeny from $\mathrm{C} 57 \mathrm{BL} / 6$ and 129 Svev did not show significant differences in freezing in the contextual and the cued test version. Compared with the $\mathrm{F}_{1}$ hybrid wild typessimilar to the water maze experiments-we observed for both contextual and cued long-term conditioning (24-hr test) a similarly ranked deficit in freezing retention in CREB mutants as in the water maze, CREB $\alpha \Delta$ mice being intermediate between wild-type and CREBcomp animals (Fig. 3A). $\mathrm{CREB} \alpha \Delta$ mice exhibited mild deficits in both contextual and cued learning, which were statistically not significant. In contrast, CREBcomp mice showed severe and statistically highly significant deficits when compared with their wild-type littermates $(P<0.001$ for both contextual and cued conditioning). To investigate whether the deficits observed were restricted to long-term retention of freezing or whether short-term learning was also affected, we performed additional experiments and tested CREB wild-type, CREB $\alpha \Delta$, and CREBcomp mice at $0.5 \mathrm{hr}$ after training. In this shortterm version of the test, however, no significant differences were observed between the three groups.

Table 2: Factor analysis of intercorrelated variables in the water maze

\begin{tabular}{|c|c|c|c|}
\hline \multirow[b]{2}{*}{ Variables } & \multicolumn{3}{|c|}{ Factor } \\
\hline & 1 & 2 & 3 \\
\hline Time near wall (\%) & -0.84 & -0.12 & -0.28 \\
\hline Search time in goal quadrant (\%) & 0.71 & -0.05 & 0.43 \\
\hline Average distance to goal & -0.88 & -0.07 & -0.40 \\
\hline Swimming speed & -0.03 & 0.97 & -0.03 \\
\hline Time in old target quadrant (\%) & 0.20 & -0.18 & 0.86 \\
\hline Crossings over old target & 0.23 & 0.14 & 0.83 \\
\hline Genotype $($ wild type $=1$, CREBcomp $=-1$ ) & 0.73 & -0.23 & -0.05 \\
\hline Variation explained $(n=84)$ & $50 \%$ & $15 \%$ & $14 \%$ \\
\hline
\end{tabular}

(Bold print) Factor scores above 0.40 are conventionally considered as meaningful.

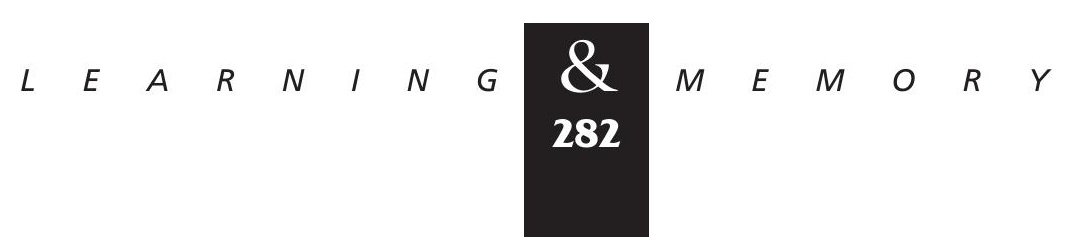




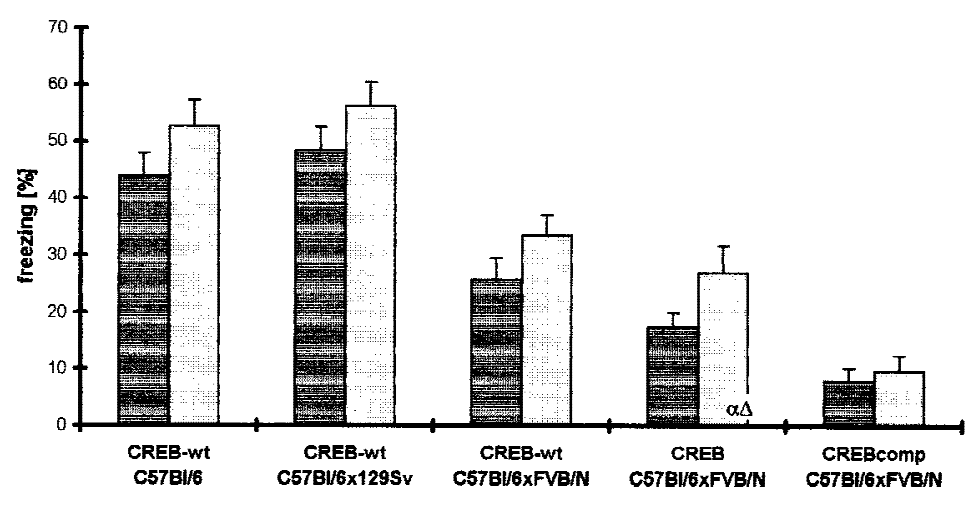

B

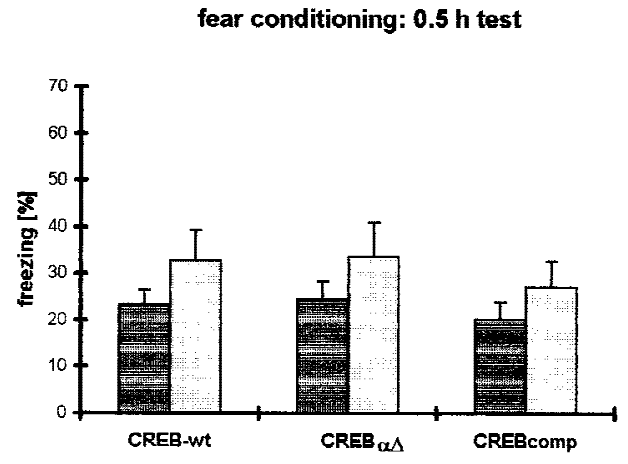

Figure 3: Fear conditioning studies demonstrate gene dosage-dependent LTM deficits in CREB mutant mice. $(A)$ In the 24-hr version of the test, one-way ANOVAs exhibit a significant difference between the five groups investigated in both contextual (dark-shaded bars) and cued (light-shaded bars) form of the test [context: $F_{(4,69)}=20.57, P<0.001$; cued: $\left.F_{(4,69)}=20.17, P<0.001\right]$. C57BL/ $6 x F V B / N F_{1}$ hybrid wild types perform significantly worse than $\mathrm{C} 57 \mathrm{BL} / 6$ or C57BL/6x129Svev wild types. Compared with their $\mathrm{F}_{1}$ hybrid wild-type littermates, $\mathrm{CREB} \alpha \Delta$ mice show mild but statistically not significant deficits. CREBcomp mice demonstrate severe and statistically highly significant deficits compared with their wild-type littermates (context and cued $P<0.001$, respectively). (B) In the 0.5 -hr version of the test, one-way ANOVAs do not exhibit significant differences between the three groups (context: $F_{(2,33)}=0.344, P=0.71$; cued: $\left.F_{(2,33)}=0.287, P=0.75\right)$.
In summary, CREBcomp but not $\mathrm{CREB} \alpha \Delta$ exhibited significant deficits in long-term but not short-term retention of freezing when compared with their wild-type littermates. It has to be pointed out, however, that the wild-type mice in the $F_{1}$ hybrid background per se showed less freezing when compared with wild-type mice of other genetic backgrounds (C57BL/6, C57BL/ 6x129Svev).

\section{CREB MUTANTS DO NOT SHOW DEFICITS IN THE SOCIAL TRANSMISSION OF FOOD PREFERENCE TASK}

When tested $24 \mathrm{hr}$ after the training session, all three groups (wild type, $\operatorname{CREB} \alpha \Delta$, CREBcomp) showed a significant preference for the cued food compared with the noncued food $(P<0.001$ for all groups; Fig. 4). The average ratio of the weight of the cued food eaten and the weight of food eaten totally was compared between wild-type mice $(75.5 \pm 7.2 \%)$ and $\mathrm{CREB} \alpha \Delta$ mutants $(79 \pm 7.2 \%)$, and no significant difference was found $(P=0.67)$. When wild-type mice were compared to CREBcomp, again no difference was observed between the two groups (Fig. 4B). Wild-type mice consumed $80.5 \pm 6.4 \%$ cued food (of food eaten totally); CREBcomp mutants, $81.5 \pm 5.5 \%(P=0.95)$. Naive mice (without scented food demonstration) did not show a preference for either of the two scented foods used in these experiments (data not shown). In summary, wild-type, $\operatorname{CREB} \alpha \Delta$, and CREBcomp mice showed intact long-term preference in this test with an equal level of performance.

\section{CREB MUTANTS EXHIBIT NORMAL LTP IN HIPPOCAMPAL CA1 AND DENTATE GYRUS NEURONS}

In the electrophysiological experiments conducted to investigate whether LTP as one form of synaptic plasticity is altered in the mutant animals, no significant differences could be detected when compared with wild-type controls (Fig. 5). This

$$
\begin{array}{llllllllllllllll}
\hline & E & A & R & N & I & N & G & \underset{2}{\mathbf{2} 83} & M & E & M & O & R & Y
\end{array}
$$


A Social transmission of food preference: CREB $\alpha \Delta$

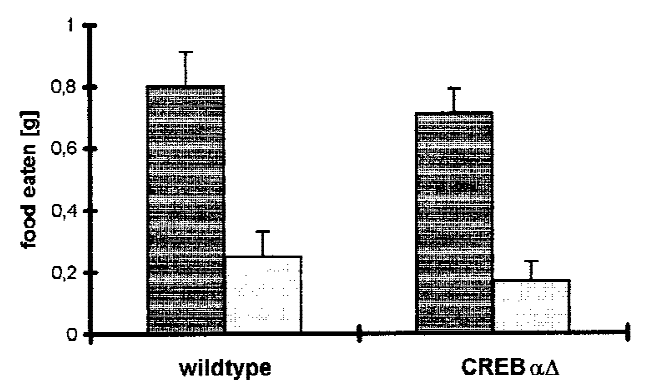

B Social transmission of food preference: CREBcomp

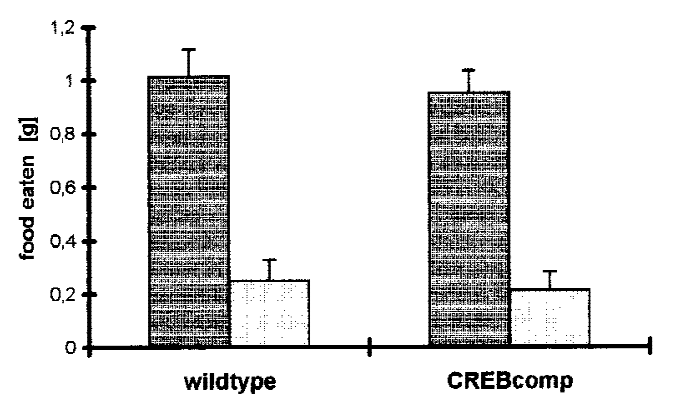

Figure 4: CREB mutants show intact LTM in the social transmission of food preference task. $(A, B)$ The social transmission of food preference tests demonstrates a clear preference for the trained food in all groups ( $P<0.001$ for all genotypes). (Dark-shaded bars) Cued; (light-shaded bars) noncued. No significant difference is found between the groups $(A: P=0.67 ; B: P=0.95)$.

holds true for both the initial size of LTP and its maintenance assessed by the percentage of potentiation $2 \mathrm{hr}$ after induction. In the CA1 region, the weak and the strong tetanization protocol evoked LTP of comparable size. Although the initial magnitude of CA1 LTP was slightly larger in wild-type animals, the difference to the two strains of mutants was not statistically distinguishable. Similarly, the induction of LTP in the dentate gyrus was unchanged in CREB $\alpha \Delta$ and CREBcomp mice when compared with wild type. When the maintenance of CA1 LTP was evaluated $2 \mathrm{hr}$ post-tetanus, neither the potentiation obtained after weak tetanization nor the potentiation induced by the strong protocol were different between CREB-deficient animals and their wild-type controls. The potentiation of CREBComp mice in the dentate gyrus tended to be reduced, but this difference was not statistically significant.

\section{Discussion}

In the present study, CREB mutant mice were impaired in water maze learning and fear conditioning but devoid of any deficits in the social transmission of food preference task and in LTP studies. The extent of impairment parallels the CREB gene dosage of the two CREB mutant strains investigated, that is, only CREBcomp mice that possess one hypomorphic CREB $\alpha \Delta$ and one CREBnull allele exhibited statistically significant deficits. In our study, CREB $\alpha \Delta$ mice (with two $\alpha \Delta$ alleles) were mildly impaired, showing only in a few parameters weak statistical significance. This contrasts with previous studies (Bourtchuladze et al. 1994; Kogan et al. 1996) that reported major deficits for CREB $\alpha \Delta$ mice in all paradigms tested. The discrepancy might be attributed to the different genetic background of the animals.

\section{INFLUENCE OF CREB ON LTM MAY DEPEND ON GENETIC BACKGROUND AND HYBRID VIGOR}

The experiments of the present study are in accordance with a recommendation of the Banbury conference to use $\mathrm{F}_{1}$ hybrids, in our case an intercross between $\mathrm{C} 57 \mathrm{BL} / 6$ and $\mathrm{FVB} / \mathrm{N}$ carrying the backcrossed CREB mutations in the sixth or seventh generation. The previous experiments with CREB $\alpha \Delta$ mice were conducted in undefined (Bourtchuladze et al. 1994) as well as $\mathrm{F}_{2}$ or $\mathrm{F}_{3}$ progeny from C57BL/6 and 129/SVJ (Kogan et al. 1996). The present study could not reproduce the observation of LTM deficits and prevention of early LTP made in CREB $\alpha \Delta$ mice earlier (Bourtchuladze et al. 1994; Kogan et al. 1996). We suggest that these results could be explained by the different genetic background and hybrid vigor (see below), because all other experimental conditions were as close as possible to those reported earlier. One cannot exclude that CREB mutants with the background used in the earlier studies suffered from mild developmental deficits (Bourtchuladze et al. 1994; Kogan et al. 1996). This might explain why already an early phase of LTP, that is, the protein synthesis independent stage, was impaired. Moreover, an increased incidence of developmental CNS defects has been reported for the $129 / \mathrm{Sv}$ background, for example, dysplasia of the corpus callosum (Lipp and Wahlsten 1992; Lipp et al., this issue). In addition to $\operatorname{CREB} \alpha \Delta$, we have investigated CREBcomp animals. These mice exhibited a decreased performance in water maze and fear

$$
\begin{array}{lllllllllllllll}
\hline & E & A & R & N & I & N & G & \begin{array}{c}
\boldsymbol{Q} \\
\mathbf{2 8 4}
\end{array} & M & E & M & O & R & Y
\end{array}
$$


A

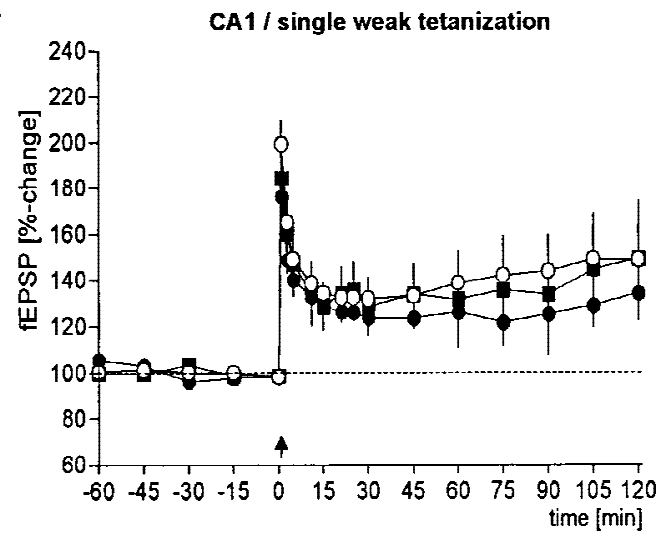

B

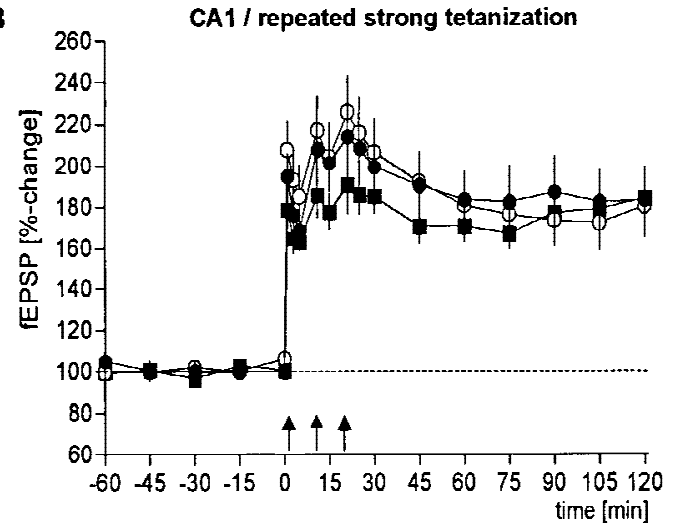

C

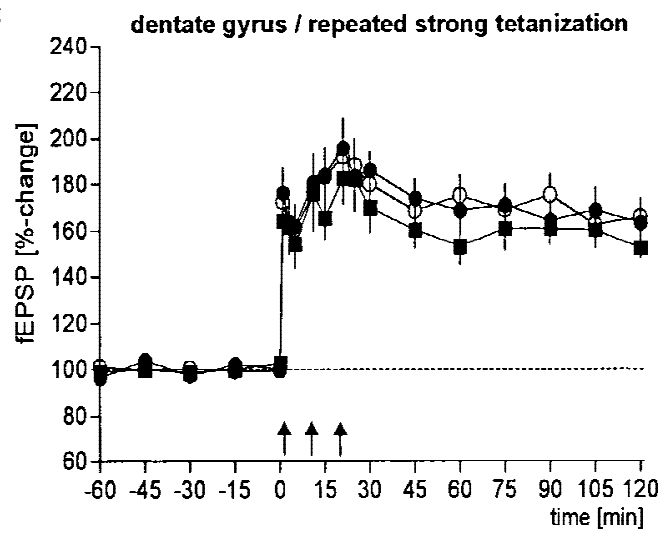

conditioning experiments but revealed normal learning in the social transmission of food preference task, as well as intact LTP. In the present study, fear conditioning experiments with wildtype $\mathrm{F}_{1}$ hybrids $(\mathrm{C} 57 \mathrm{BL} / 6 \mathrm{xFVB} / \mathrm{N})$ demonstrated less freezing than wild-type mice of other genetic backgrounds, that is, pure $\mathrm{C} 57 \mathrm{BL} / 6$ or $\mathrm{C} 57 \mathrm{BL} /$ $6 \times 129 /$ Sv (Fig. 3). Thus, given the reduced freezing of the wild-type animals, mild deficits in the mutants (e.g., in CREB $\alpha \Delta$ ) may have been too small
Figure 5: Hippocampal LTP in the CA1 region and in the dentate gyrus is unchanged in CREB mutant mice. LTP could be induced and maintained in all groups investigated, that is, in wild-type (O), $\operatorname{CREB} \alpha \Delta(\mathbf{O})$, and CREBcomp ( $\mathbf{\square})$ mice, irrespective of whether a single weak $(A)$ or a repeated strong tetanization protocol $(B, C)$ was applied. Statistical significant differences between the groups can be neither detected in the initial magnitude of potentiation nor in the maintanance (sample size for wild-type, $\operatorname{CREB} \alpha \Delta$, and CREBcomp animals: weak tetanus CA1, $n=9, n=5, n=5$, respectively; strong tetanus CA1: $n=9, n=9, n=5$; strong tetanus dentate gyrus, $n=9, n=9, n=7)$. In all CA1 experiments, potentials from a second independent, nontetanized control input were recorded. No influence on baseline potentials was observed during the recorded period.

to reach statistical significance. However, regular performance of $F_{1}$ hybrid wild types and both mutant strains in the social transmission of food preference test as well as no changes in LTP studies indicates that mice in the $\mathrm{C} 57 \mathrm{BL} / 6 \mathrm{xFVB} / \mathrm{N}$ background are not generally compromised for memory testing. The $\mathrm{F}_{1}$ crosses used here showed the behavioral hybrid vigor that can be expected from crosses between near inbred lines. Thus, the $\mathrm{F}_{1}$ hybrid wild-type mice used in the water maze learned equally or better than a large sample of $\sim 600 \mathrm{~F}_{2}$ wild-type controls and showed practically no floating (data not shown). Taken together, it appears that hybrid vigor has reduced the impact of CREB $\alpha \Delta$ in behavioral and physiological tests, similarly as it has been demonstrated for pharmacological manipulations of water maze learning in the strains $\mathrm{C} 57 \mathrm{BL} / 6$, DBA, and their $\mathrm{F}_{1}$ hybrids (Upchurch et al. 1988). On the other hand, the persistence of deficits in the CREBcomp hybrids implies that the consequences of the compound mutation are robust and reliable. Likewise, the reduction of morphine abstinence in CREB $\alpha \Delta$ mice is preserved when examined in the $\mathrm{F}_{1}$ hybrid $\mathrm{C} 57 \mathrm{BL} / 6 \mathrm{xFVB} / \mathrm{N}$ background (Maldonado et al. 1996; R. Maldonado, P. Gass, and G. Schütz, unpubl.).

\section{DEFICITS IN WATER MAZE AND FEAR}

\section{CONDITIONING TASKS DEPEND ON GENE DOSAGE}

In addition to differences in the genetic background and hybrid vigor, a gene dosage effect could account for the changes obtained in the behavioral tests. A stepwise reduction in CREB gene dosage was accompanied by an increasing severeness of behavioral deficits. Thus, in the water maze

$$
\begin{array}{llllllllllllllll}
\hline & E & A & R & N & I & N & G & \begin{array}{l}
\boldsymbol{Q} \\
\mathbf{2 8 5}
\end{array} & M & E & M & O & R & Y
\end{array}
$$


task as well as in contextual and cued fear conditioning, CREB $\alpha \Delta$ mice exhibited only a trend to an impaired performance, but CREBcomp mice displayed severe and statistically highly significant deficits (Figs. 2 and 3). These findings are in line with recent studies in Drosophila and Aplysia demonstrating that the ratio of CREB activators and CREB suppressor proteins is crucial for the development of LTM (Yin et al. 1994, 1995; Bartsch et al. 1995). Both transgenic manipulations in Drosopbila leading to an increased activator/suppressor ratio and the application of antibodies to a CREB suppressor protein in Aplysia resulted in enhanced LTM formation and long-term facilitation, respectively (Yin et al. 1994, 1995; Bartsch et al. 1995). Similar to a previous study by Kogan et al. (1996), we observed a marked improvement of both CREB mutant strains in the water maze performance when we used a protocol with increased training intensity and frequency. In contrast to earlier studies, however, only CREBcomp mice displayed a clear deterioration of learning, whereas $\mathrm{CREB} \alpha \Delta$ mice were practically indistinguishable from wild-type controls (Bourtchuladze et al. 1994; Kogan et al. 1996). Such discrepancies probably reflect differences in genetic background and hybrid vigor (see above).

It appears likely that the distinct deficits of the CREBcomp mice in swimming navigation are the result of a reduction of CREB protein below a critical threshold. It is not clear, however, whether the deterioration in learning scores and spatial retention is caused by a deficit in the molecular mechanisms of spatial memory or by a defect in some other form of plasticity. Our data provide evidence that thigmotaxis in the water maze, which at the beginning of training is found in all genotypes, is the main predictor of poor acquisition and low probe trial scores. A high number of CREBcomp mice showed persistent thigmotaxis throughout training, whereas a minority learned well and showed decent probe trial scores. This indicates an ability to develop spatial memory in the presence of the CREBcomp mutation. Theoretically, increased thigmotactic swimming could also result from an impaired spatial memory. However, the results of the factor analysis showing no correlations between genotype and a spatial memory factor do not support this notion (Table 2). In addition, the intense training schedule included a platform reversal. The very pronounced increase in escape time after the platform reversal indicates that most CREBcomp mice had learned the plat- form position, possibly by means of alternative search strategies (Fig. 1A). Second, it indicates a problem of some of these CREBcomp mice in rapid switching to a search strategy for a new platform location. Taking into account the lack of differences in synaptic plasticity as measured by LTP, these observations suggest that mice with low levels of CREB were suffering from impaired behavioral flexibility, being unable to switch to more efficient search strategies. In support of this notion, CREBcomp mice showed also increased and persisting levels of thigmotaxis in the open field, despite a high locomotor activity (data not shown). Taken together, the data suggest that CREB in mammals could also play a more general role in noncognitive neural adaptivity.

CREBcomp mutants showed significantly reduced freezing to both auditory and contextual cues as compared with both CREB $\alpha \Delta$ and CREB wild-type controls. This parallels the finding in the water maze and strongly suggests a gene dosage effect. The freezing deficit of CREBcomp mice primarily in the 24-hr test but not in the 0.5-hr test is clearly consistent with a role of CREB in LTM, most likely in the amygdala and hippocampus. However, freezing also depends on the spontaneous activity level of the mice. Active mice such as $\mathrm{F}_{1}$ hybrids show lower levels of freezing, but this may not necessarily represent an indicator of impaired memory. Thus, as in swimming navigation and open field, it cannot be excluded that CREBcomp mice have also difficulties in long-term adaptation and control of intrinsic behaviors interfering with the learned appropriate response (freezing). This would again also imply cellular mechanisms more related to habituation and adaptation than to specific memory processes and their related neuronal circuitries.

\section{CONCLUSIONS}

The present study demonstrates gene dosagedependent learning deficits in mice with hypomorphic CREB alleles. Compared with earlier studies of $\mathrm{CREB} \alpha \Delta$ mice in a different genetic background, deficits observed in CREB $\alpha \Delta$ mice were mild (water maze, fear conditioning) or absent (social transmission of food preference, LTP), most likely owing to hybrid vigor resulting from the use of $F_{1}$ hybrids. Whereas CREB seems to play a unique role in memory in Aplysia and Drosopbila, more complex pathways may exist in mammals, which may compensate for the reduced levels of CREB in the

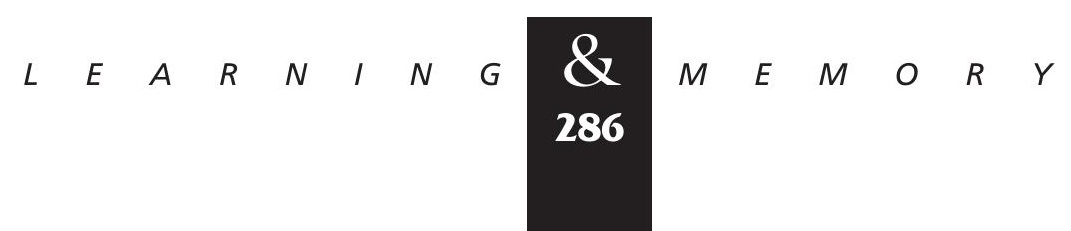


CNS. One compensatory mechanism observed in mice with a loss of the CREB $\alpha$ and $\Delta$ isoforms is the up-regulation of the CREB $\beta$ isoform (Blendy et al. 1996). Further reduction of gene dosage was achieved by generating CREBcomp mice with only one intact $\beta$-allele. In addition, up-regulation of CREM, which is also expressed in the nervous system, may compensate for the reduced levels of CREB activity (Hummler et al. 1994; Blendy et al. 1996). Further experiments are required to define the function of CREB and related proteins in vertebrate synaptic plasticity and memory formation. Comparative analysis of the reliable phenotype of the CREBcomp $F_{1}$ hybrids with (upcoming) conditional and tissue-specific null mutations of the CREB gene will allow further characterization of the role of CREB in learning and memory.

\section{Acknowledgments}

We are indebted to Dr. Richard G.M. Morris for critically reading the manuscript. We wish to acknowledge the excellent technical assistance of Heike Glaser, Sabine Hartmann, Diana Koch, Rosmarie Lang, Stefanie Ridder, and Christiane Zacher. We extend our thanks to Dr. Lutz Edler for help with the statistical analysis. This work was supported by the Deutsche Forschungsgemeinschaft to P.G. and G.S. (ZI 110/22-1; UN 34/19-1) as well as to U.F. (FR 1034/4-1), by the "Volkswagen-Stiftung" to G.S., by the Land Sachsen-Anhalt to U.F. (2521A/0086H), by the Swiss National Foundation for Scientific Research to H.P.L. (31-466691.96) and to D.P.W. (31-42347.94), and by the Human Frontier Science Program to H.P.L.

The publication costs of this article were defrayed in part by payment of page charges. This article must therefore be hereby marked "advertisement" in accordance with 18 USC section 1734 solely to indicate this fact.

\section{References}

Bailey, C.H., D. Bartsch, and E.R. Kandel. 1996. Toward a molecular definition of long-term memory storage. Proc. Natl. Acad. Sci. 93: 13445-13452.

Banbury Conference on Genetic Background in Mice. 1997. Mutant mice and neuroscience: Recommendations concerning genetic background. Neuron 19: 755-759.

Bartsch, D., M. Ghirardi, P.A. Skehel, K.A. Karl, S.P. Herder, M. Chen, C.H. Bailey, and E.R. Kandel. 1995. Aplysia CREB2 represses long-term facilitation: Relief of repression converts transient facilitation into long-term functional and structural change. Cell 83: 979-992.

Blendy, J.A., K.H. Kaestner, W. Schmid, P. Gass, and G. Schütz. 1996. Targeting of the CREB gene leads to upregulation of a novel CREB mRNA isoform. EMBO J. 15: 1098-1106.

Bliss, T.V. and G.L. Collingridge. 1993. A synaptic model of memory: Long-term potentiation. Nature 361: 31-39.
Bourtchuladze, R., B. Frenguelli, J. Blendy, D. Cioffi, G. Schütz, and A.J. Silva. 1994. Deficient long-term memory in mice with a targeted mutation of the CAMP responsive element binding (CREB) protein. Cell 79: 59-68.

Dash, P.K., B. Hochner, and E.R. Kandel. 1990. Injection of the cAMP response element into the nucleus of Aplysia sensory neurons blocks long-term faciliation. Nature 345: 718-721.

Frank, D.A. and M.E. Greenberg. 1994. CREB: A mediator of long-term memory from mollusks to mammals. Cell 79: 5-8.

Frey, U. and R.G.M. Morris. 1997. Synaptic tagging and long-term potentiation. Nature 385: 533-536.

Frey, U., M. Krug, K.G. Reymann, and H. Matthies. 1988. Anisomycin, an inhibitor of protein synthesis, blocks late phases of LTP phenomena in the hippocampal CA1 region in vitro. Brain Res. 452: 57-65.

Frey, U., M. Müller, and D. Kuhl. 1996. A different form of long-lasting potentiation revealed in tissue plasminogen activator mutant mice. J. Neurosci. 16: 2057-2063.

Gerlai, R. 1996. Gene-targeting studies of mammalian behavior: Is it the mutation or the background genotype? Trends Neurosci. 19: 177-181.

Giese, K.P., N.B. Fedorov, R.K. Filipkowski, and A.J. Silva. 1998. Autophosphorylation at Thr286 of the $\alpha$ calcium-calmodulin kinase II in LTP and learning. Science 279: $870-873$.

Guzowski, J.F. and J.L. McGaugh. 1997. Antisense oligodeoxynucleotide-mediated disruption of hippocampal cAMP response element binding protein levels impairs consolidation of memory for watermaze training. Proc. Natl. Acad. Sci. 94: 2693-2698.

Hsiao, K., P. Chapman, S. Nilsen, C. Eckman, Y. Harigaya, S. Younkin, F. Yang, and G. Cole. 1996. Correlative memory deficits, $A \beta$ elevation, and amyloid plaques in transgenic mice. Science 274: 99-102.

Hummler, E., T.J. Cole, J.A. Blendy, R. Ganss, A. Aguzzi, W. Schmid, F. Beermann, and G. Schütz. 1994. Targeted mutation of the cAMP response element binding protein (CREB) gene: Compensation within the CREB/ATF family of transcription factors. Proc. Natl. Acad. Sci. 91: 5647-5651.

Kogan, J.H., P.W. Frankland, J.A. Blendy, J. Coblentz, Z. Marowitz, G. Schütz, and A.J. Silva. 1996. Spaced training induces normal long-term memory in CREB mutant mice. Curr. Biol. 7: 1-11.

Lathe, R. 1996. Mice, gene targeting and behaviour: More than just genetic background. TINS 19: 183-186.

Lipp, H.P. and D. Wahlsten. 1992. Abscence of the corpus callosum. In Genetically defined animal models of neurobehavioural dysfunctions (ed. P. Driscall), pp. 217-252. Birkhäuser, Boston, MA.

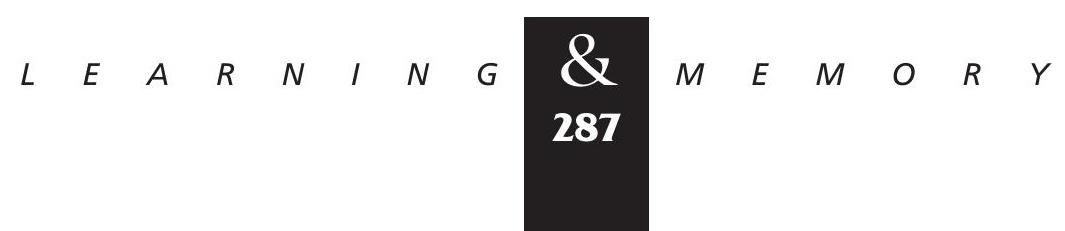




\section{Gass et al.}

Lipp, H.P. and D.P. Wolfer. 1998. Genetically modified mice and cognition. Curr. Opin. Neurobiol. 8: 272-280.

Lipp, H.H., C. Buechel, R. Waanders, S. Sibold-Savina, F. Magara, and D.P. Wolfer 1998. Swimming navigation learning, size variations, and agenesis of the corpus callosum in mice: No major effects but subtle and strain specific influences on spatial memory within 129 strains. Learn. \& Mem. (this issue).

Maldonado, R., J.A. Blendy, E. Tzavara, P. Gass, B.P. Roques, J. Hanoune, and G. Schütz. 1996. Reduction of morphine abstinence in mice with a mutation in the CREB gene. Science 273: 657-659.

Morris, R.G.M., P. Garrud, J.N.P. Rawlins, and J. O'Keefe. 1982. Place navigation impaired in rats with hippocampal lesions. Nature 297: 681-683.

Owen, E.H., S.F. Logue, D.L. Rasmussen, and J.M. Wehner. 1997. Assessment of learning by the Morris water task and fear conditioning in inbred mouse strains and F1 hybrids: Implications of genetic background for single gene mutations and quantitative trait loci analyses. Neurosci. 80: 1087-1099.

Rudolph, D., A. Tafuri, P. Gass, G.J. Hämmerling, B. Arnold, and G. Schütz. 1998. Impaired fetal T-cell development and perinatal lethality in mice lacking the cAMP response element binding protein (CREB). Proc. Natl. Acad. Sci. 95: 4481-4486.

Upchurch, M., J.I. Pounder, and J.M. Wehner. 1988. Heterosis and resistance to DFP effects on spatial learning in C57BL x DBA hybrids. Brain Res. Bull. 21: 499-503.

Wolfer, D.P., U. Müller, M. Stagliar, and H.P. Lipp. 1997. Assessing the effects of the 129/Sv genetic background on swimming navigation learning in transgenic mutant: A study using mice with a modified beta-amyloid precursor protein gene. Brain Res. 771: 1-13.

Yin, J.C.P., J.S. Wallach, M. Del Vecchio, E.L. Wilder, H. Zhou, W.G. Quinn, and T. Tully. 1994. Induction of a dominant negative CREB transgene specifically blocks long-term memory in drosophila. Cell 79: 49-58.

Yin, J.C.P., M. Del Vecchio, H. Zhou, and T. Tully. 1995. CREB as a memory modulator: Induced expression of a dCREB2 activator isoform enhances long-term memory in drosophila. Cell 81: 107-115.

Received March 11, 1998; accepted in revised form July 17, 1998. 


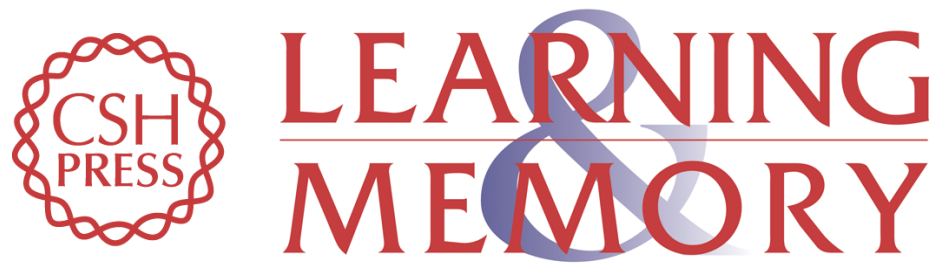

\section{Deficits in Memory Tasks of Mice with CREB Mutations Depend on Gene Dosage}

Peter Gass, David P. Wolfer, Detlef Balschun, et al.

Learn. Mem. 1998, 5:

Access the most recent version at doi:10.1101//m.5.4.274

References This article cites 26 articles, 8 of which can be accessed free at: http://learnmem.cshlp.org/content/5/4/274.full.html\#ref-list-1

License

Email Alerting Receive free email alerts when new articles cite this article - sign up in the box at the Service top right corner of the article or click here. 